\title{
Hospital costs of extracorporeal life support therapy
}

\author{
WM van den Bergh", Dutch ECLS Study Group \\ From ESICM LIVES 2015 \\ Berlin, Germany. 3-7 October 2015
}

\section{Introduction}

Extracorporeal life support (ECLS) seems an efficient therapy for acute, potentially reversible cardiac or respiratory failure, when conventional therapy has been inadequate, or as bridge to transplant, but there is no evidence for cost-effectiveness. Our aim was to conduct an exploration of the hospital costs of ECLS therapy.

\section{Objectives}

Single-center retrospective exploratory cohort cost study. The study is performed from a hospital perspective with a time horizon of patients' complete hospital admission in which they received ECLS.

\section{Methods}

All 67 consecutive adult patients who were admitted to the ICU of the University Medical Center Groningen (the Netherlands) in the period 2010 to 2013 and received ECLS treatment were included. The bottom-up micro costing method was used. Medical costs were estimated by multiplying every registered healthcare consumption with unit prices. Unit prices were largely based on Dutch reference prices. For each patient the personnel costs and material costs were assessed in detail. The costs of ECLS were differentiated in costs of procedures and costs of daily surcharge of therapy. Procedure related costs were subdivided in costs of devices and disposables, costs of additional human resources and surgery hours.

In order to estimate costs of ECLS therapy based on indication all patients were categorized into six different subgroups: respiratory - bridge to recovery, respiratory bridge to transplant, cardiac - bridge to recovery, cardiac bridge to transplant, cardiac - post-cardiotomy, and ECPR.

\section{Results}

The mean age was 46 years, female sex 66\%, APACHE II score 24, ECLS duration $135 \pm 163$ hours, ICU length
Table 1.

\begin{tabular}{lll}
\hline Patient category & $\begin{array}{l}\text { Mean total } \\
\text { hospital cost }(\boldsymbol{\epsilon})\end{array}$ & $\begin{array}{l}\text { Mean cost per } \\
\text { hospital day }(\boldsymbol{\epsilon})\end{array}$ \\
\hline All patients & 106.263 & 2,796 \\
\hline $\begin{array}{l}\text { respiratory - bridge to } \\
\text { recovery }\end{array}$ & 110,553 & 2,571 \\
\hline $\begin{array}{l}\text { respiratory - bridge to } \\
\text { transplant }\end{array}$ & 153,345 & 2,513 \\
\hline $\begin{array}{l}\text { cardiac - bridge to } \\
\text { recovery }\end{array}$ & 69,803 & 5,369 \\
\hline $\begin{array}{l}\text { cardiac - bridge to } \\
\text { bridge/transplant }\end{array}$ & 66,971 & 2,480 \\
\hline $\begin{array}{l}\text { cardiac - post } \\
\text { cardiotomy }\end{array}$ & 68,582 & 5,275 \\
\hline ECPR & 51,997 & 3,999 \\
\hline
\end{tabular}

[Hospital cost per category]

of stay $18 \pm 22$, hospital length of stay $38 \pm 45$, and in hospital mortality $68 \%$. The mean total hospital costs were $€ 106.263$ ( $€ 83.841$ - $€ 126.266)$ per patient. On average, $52 \%$ of the total costs arose from hospital nursing days and $11 \%$ of direct procedure related ECLS costs. Surgery and diagnostics represented a vast amount of the remaining costs.

\section{Conclusions}

This large and detailed economic evaluation of hospital costs of ECLS therapy in the Netherlands showed that mean total hospital cost of ECLS treatment are $€ 106.263$ per patient. The majority of the costs are composed of hospital nursing days.

Published: 1 October 2015

doi:10.1186/2197-425X-3-S1-A947

Cite this article as: van den Bergh and : Hospital costs of extracorporeal life support therapy. Intensive Care Medicine Experimental 2015 3(Suppl 1): A947. 